\title{
Is There an App for That? Apps for Post-Secondary Students With Attention Hyperactivity Disorder (ADHD)
}

\author{
Catherine S. Fichten ${ }^{1}$, Alice Havel ${ }^{2}$, Mary Jorgensen ${ }^{3}$, Rosie Arcuri ${ }^{3}$, Christine $\mathrm{Vo}^{3}$ \\ ${ }^{1}$ Dawson College, McGill University, Jewish General Hospital, Adaptech Research Network, Montreal, Canada \\ ${ }^{2}$ Dawson College and Adaptech Research Network, Montreal Canada \\ ${ }^{3}$ Adaptech Research Network, Montreal, Canada \\ Correspondence: Catherine S. Fichten, Department of Psychology, Dawson College, Montreal, Quebec, H3Z 1A4, \\ Canada.
}

Received: August 5, 2020

doi:10.11114/jets.v8i10.4995
Accepted: Sep. 1, $2020 \quad$ Online Published: Sep. 2, 2020

URL: https://doi.org/10.11114/jets.v8i10.4995

\begin{abstract}
We compiled a comprehensive list of apps related to coping with academic work by post-secondary students with attention deficit hyperactivity disorder (ADHD) by examining 23 recent sources. Most of these were based on the opinion of single individuals, including persons with ADHD and experts. To discover relatively common apps, we summed the number of sources that mentioned each app and then checked with the Apple App Store and the Google Play Store to ensure availability in the summer of 2020. In the process it became apparent that while most apps directly supported schoolwork (e.g., calendars, timers, reminders) there were a variety of apps that, while not directly related to schoolwork, were apps that can support academic achievement by dealing with daily life demands (not ADHD therapy or assessment). We categorized apps related to both schoolwork as well as to aspects of daily life demands that can make academic work easier. Here we present the 20 most frequently mentioned schoolwork related apps and the eight most frequently mentioned daily life demands apps. Our findings suggest that if access coordinators, campus disability service providers, ADHD coaches and students with ADHD focus solely on schoolwork related apps, they will be missing an important part of the equation. They need to broaden their scope to ensure that students also have the help they need to structure and manage their daily life responsibilities, rather than simply focusing on doing schoolwork.
\end{abstract}

Keywords: attention deficit hyperactivity disorder, ADHD, apps, post-secondary, college students, schoolwork

\section{Introduction}

\subsection{Introduction of the Problem}

Attention deficit hyperactivity disorder (ADHD) affects between $28 \%$ and $38 \%$ of post-secondary students with disabilities (Gagné, Tremblay, \& Bussières, 2020; Fichten et al., 2019). It often co-occurs with learning disabilities (DuPaul, Gormley, \& Laracy, 2013). ADHD symptoms can include: impulsiveness, disorganization, difficulty prioritizing tasks, poor time management skills, problems focusing on a task, trouble multitasking, excessive activity or restlessness, poor planning, low frustration tolerance, frequent mood swings, difficulty following through and completing tasks, hot temper, and trouble coping with stress (Mayo Clinic, 2019).

\subsection{Importance of the Problem}

Given such symptoms and the importance of time management and organization skills for success in college, it is not surprising that college students with ADHD often have academic difficulties (Green \& Rabiner, 2012). Moreover, data show that students with ADHD have difficulty with personal situations (e.g., study habits, motivation), and course-related self-efficacy (e.g., time management, keeping up-to-date with schoolwork) (Budd, Fichten, Jorgensen, Havel, \& Flanagan, 2016). The following school related ADHD symptoms and challenges were recently reported by 52 college students: "staying focused, managing time, extensive writing assignments, reading comprehension of textbooks or academic publications, organization, completing homework, memorizing and retrieving information from memory, following multistep directions, expressing thoughts or opinions clearly, following others when they speak in conversation, applying different approaches to one problem, and initiating activities, tasks or independent ideas" (Kreider, Medina, \& Slamka, 
2019, Table 2). Considering these difficulties, it is not surprising that the academic performance of post-secondary students with ADHD is often poor (Budd et al., 2016).

\subsection{Relevant Scholarship}

The American Academy of Child and Adolescent Psychiatry (2019) noted that it can be normal for students to experience a lack of focus as well as feelings of distraction, being overwhelmed, and disorganization when they pursue college studies. College students often have demanding schedules with various responsibilities; coursework being just one of them (Ahrens, Lee, Zweibruck, Tumanan, \& Larkin, 2019). Children and Adults with Attention-Deficit/Hyperactivity Disorder (CHADD, 2018) commented that, "self-care practices are part of the behavioral management of ADHD. Sometimes referred to as 'coping skills,' they are the structures that allow someone to meet daily life demands." These include activities such as managing one's finances, relationships, sleep, and jobs.

A recent EDUCAUSE review (Seilhamer, Chen, Bauer, Salter, \& Bennett, 2018) reported that 99\% of American college students owned a smartphone. In addition, in their study of 46 post-secondary students with disabilities and a matched sample of 46 students without disabilities Chmiliar and Anton (2018) found 100\% smartphone ownership.

While there are many listings of potentially useful smartphone and tablet apps for students with ADHD, we were unable to find any studies that actually showed apps to be effective in improving the academic outcomes of students. Indeed, the only empirical investigation (Gortsema, 2019) showed that within a sample of 14 "neurodiverse" students, including some students with ADHD, 10 of 21 apps listed were identified as being helpful, although only one app, MyHomework, was selected by more than one student. Nevertheless, there are many articles published for students with ADHD with titles such as "the best 10 apps for learners with ADHD." But how many of these are idiosyncratic preferences of specific individuals and how many are frequently used or excellent apps? Although there is a scientific literature on apps for students with ADHD, studies typically involve therapy and assessment (see Păsărelu, Andersson, \& Dobrean, 2020).

\subsection{Goals and Their Correspondence to Research Design}

Our goal was to compile a comprehensive list of apps available in 2020 related to coping with academic work by postsecondary students with ADHD. When we explored apps, it became apparent that most apps directly supported schoolwork (e.g., calendars, timers, reminders). However, we also came across a variety of apps that, while not directly related to schoolwork, were apps that can support academic achievement by dealing with daily life demands. Therefore, we categorized and examined apps for post-secondary students with ADHD related to both schoolwork, as well as to aspects of daily life demands that made doing schoolwork easier.

\section{Method}

Our goal was to compile a comprehensive list of apps related to the academic performance of post-secondary students with ADHD. To achieve this, in the summer of 2020 we examined 23 sources. The selection of these sources was based on web searches using Google and Google Scholar for the years 2017 to 2020 (July) with the following key words "ADHD and apps and college." In addition, we checked the past three years of ADDitude Magazine, and the web site of the Canadian ADHD Resource Alliance (CADDRA) as well as the archive of the Canadian Association of Disability Service Providers in Post-Secondary Education (CADSPPE). We also joined and examined apps posted on four ADHD Facebook groups (ADHD West Island Parents, How to ADHD, ADHD Foundation, and ADHD Apps and Technology). In addition, we looked through the Apple App Store and the Google Play Stores with the keyword ADHD and examined the first 20 apps that appeared and were associated with education and schoolwork apps, rather than with therapy or assessment. We also referred to a 2018 Adaptech Research Network study involving focus group participants with ADHD. References to published sources for the apps are available in Appendix A.

\subsection{Exclusions}

We discarded apps that were for children, those that required an external support (e.g., Livescribe, Tile) and those that attempted to teach students (e.g., Math Ninja) or treat ADHD (e.g., Lumosity). To ensure that the apps are available in 2020 we visited the Apple App Store and the Google Play Store in August 2020.

\section{Results}

We posted an annotated list of all apps available in August 2020, along with the frequency with which each was mentioned by our 23 sources on the Adaptech Research Network web site. ${ }^{1}$

We provide schoolwork related apps available for iPhones or Android phones in Table 1. This shows that the most common apps relate to task management. Features include note taking, daily planners, prioritizers, progress trackers, reminders,

\footnotetext{
${ }^{1} \mathrm{https} / / /$ adaptech.org/publications/comprehensive-list-of-apps-related-to-the-academic-performance-of-post-secondarystudents-with-adhd/
} 
and apps that acknowledge task completion. Other commonly noted apps include those that deal with focusing and distraction management, time management, and organization. Literacy and text-to-speech apps are also relatively common. Table 2 shows frequently mentioned daily life demands apps. The most common apps relate to budget and financial tacking and to email management.

Table 1. Frequently mentioned schoolwork related apps

\begin{tabular}{|c|c|c|c|c|}
\hline $\begin{array}{c}\text { Total } \\
\text { Mentions }\end{array}$ & $\begin{array}{c}\text { Available } \\
\text { for iOS }\end{array}$ & $\begin{array}{c}\text { Available } \\
\text { Android }\end{array}$ & Name of App & Brief Description \\
\hline 9 & Yes & Yes & Evernote & Task management and note taking app that helps keep all notes in one place \\
\hline 6 & Yes & Yes & Microsoft To Do / Wunderlist & Task management app with a daily planner. Breaks tasks down into simple steps \\
\hline 5 & Yes & Yes & Todoist & Task management. Prioritizes tasks, daily and weekly goals. Rewards for completion \\
\hline 4 & Yes & Yes & Asana & Task management. Helps set goals and track progress using a Gantt chart \\
\hline 3 & Yes & Yes & Remember the Milk & Task management. Reminders by email, text, and Twitter. Works across all devices \\
\hline 3 & Yes & No & Due & Task management. 'Auto Snooze' repeatedly reminds the user of overdue reminders \\
\hline 4 & Yes & Yes & Focus@Will & Focusing music subscription service. Customizes music for different activities \\
\hline 3 & Yes & No & Forest & Focusing. Virtual tree helps avoid one's smartphone for specific time periods \\
\hline 6 & Yes & Yes & RescueTime & Time management app. Tracks time spent on apps, websites, and specific documents \\
\hline 4 & Yes & Yes & Time Timer & Time management. Visual countdown timer. Helps notice time remaining for a task \\
\hline 4 & Yes & Yes & IFTTT (If This Then That) & Organization. Connects apps, services, and devices to automate tasks \\
\hline 3 & Yes & Yes & Dropbox & Organization. Online file hosting. Store all files in the same place, across all devices \\
\hline 3 & Yes & Yes & Dragon Anywhere & Literacy. Dictation for writing documents \\
\hline 3 & Yes $^{1}$ & Yes $^{1}$ & Learning Ally & Text-to-speech and human-narrated audio textbook library \\
\hline 3 & Yes & Yes & Voice Dream Reader & Text-to-speech. Provides reading with synchronized highlighting \\
\hline 5 & Yes & No & Mindnode 5 & Mind-mapping. Brainstorming tool. Users can add visual tags to track progress \\
\hline 3 & Yes & Yes & Quizlet & Study app. Uses flashcards and games to facilitate user learning \\
\hline
\end{tabular}

${ }^{1}$ United States only.

2 iPad only

Table 2. Frequently mentioned daily life demands apps

\begin{tabular}{cccll}
\hline $\begin{array}{c}\text { Total } \\
\text { Mentions }\end{array}$ & $\begin{array}{c}\text { Available } \\
\text { for iOS }\end{array}$ & $\begin{array}{c}\text { Available } \\
\text { Android }\end{array}$ & Name of App & Brief Description \\
\hline 4 & Yes & Yes & Mint & $\begin{array}{l}\text { Budget and finance tracking. Makes money management simpler and more seamless } \\
\text { Budget and finance tracking. Helps track money, credit cards, accounts and spending } \\
2\end{array}$ \\
Yes & Yes & YNAB (You Need a Budget) \\
3 & Yes & Yes & Unroll.Me & Email management. Helps unsubscribe with one click \\
2 & Yes & Yes & Boomerang Mail & Time management. Times daily routines such as morning, going to work, and sleep \\
3 & Yes & No & Routinist & Sleep monitoring. Sets wake up alarm when users are in their lightest sleep phase \\
3 & Yes & Yes & Sleep Cycle & Focusing. Reduces distraction, improves sleep. Sounds of the environment block noise \\
2 & Yes & Yes & White Noise & Telephone. Phone number, text, voicemail, voicemail transcription across all devices \\
\hline
\end{tabular}

${ }^{1}$ United States only.

\section{Discussion}

Given the symptoms and academic challenges that students with ADHD often face (Budd et al., 2016; Kreider et al., 2019; Mayo Clinic, 2019) it is not surprising that the most frequently noted apps related to schoolwork. However, as mentioned earlier (Ahrens et al., 2019; CHADD, 2018), students with ADHD also have daily life demands that must be addressed in order to succeed in school. Consistent with their views, we also found a variety of frequently mentioned apps related to self-care practices that can facilitate academic success.

\subsection{Schoolwork}

Our findings show that the most frequently mentioned apps for post-secondary students with ADHD deal with schoolwork related topics. These deal with task management, focusing and managing distraction, time management and organization. Although literacy software was also relatively frequently mentioned, this may be linked to the common comorbidity of a learning disability. Alternately, students with ADHD may use text-to-speech to assist in reading comprehension and as a tool for revision. Many students with ADHD tend to skip over words and lines while reading and do not notice missing words or errors due to inattention. It is noteworthy that many of the apps work across a variety of devices, including computers and tablets along with smartphones. This allows students to access their information wherever they are.

\subsubsection{Task Management}

Features of many of the task managing apps include keeping notes and documents in one place to prevent students from losing these. Some apps incorporate a "smart" personalized daily planner that gives suggestions to update the student's 
to-do-list. Other apps break tasks down into simple steps, help students stay on track by allowing them to add due dates and set reminders and send students notifications. Students can get reminders from various sources, including e-mail, text, instant messaging, and mobile apps. Some apps allow students to color-code their to-do lists and identify recurrent tasks. Some apps provide automatic tracking of how long a student spends using specific apps and websites, as well as time spent working on certain documents; this gives students information about what gets in the way of their productivity. One app automatically adds the event in a calendar when the student receives an email about an event. Another task managing app has an 'auto snooze' feature that repeatedly reminds the user of overdue reminders until they are marked as complete, rescheduled, or the 'auto snooze' feature is turned off. Task managing features can also help students prioritize their tasks, allow them to set daily and weekly goals, track their progress in completing these goals and reward students when they complete a task. An interesting feature of one of the apps (Asana) is a Gantt chart to build a timeline and help students recognize how much work they have left to do.

\subsubsection{Focusing}

Some apps in this category work by managing distraction through blocking websites, apps, or the internet for a specific duration. Other apps aim to keep the student focused by customizing and slightly changing the characteristics of music at specific time intervals. In an interesting app in this category (Forest) students determine how long they wish to stay away from their phone. The user then starts the app and a virtual tree is planted. The tree continues to grow as long as the student does not use their smartphone. If the student uses their smartphone before the specified time expires the tree will die. Users can grow multiple trees, create forests, and compare these with their friends to stay motivated.

\subsubsection{Time Management}

Several apps in this category provide automatic tracking of how long an individual spends on apps and websites, as well as on working on specific documents. In this way the app gives students information about what gets in the way of their productivity. Another provides a means of inserting information in apps so that there is no need for retyping (e.g., get an alert as soon as there's a new Google listing that matches one's search).

\subsubsection{Organization}

One of these apps is an online file hosting service that allows students to store all their files in the same place and access their files on all their devices. Another provides a means of inserting information in apps so that there is no need to retype them (e.g., get an alert as soon as there's a new Google listing that matches your search).

\subsection{Daily Life Demands}

There were also a variety of apps related to daily life demands. These include budgeting and managing one's money, organizing emails, focusing to help with sleep, and managing time (e.g., how long it takes to have breakfast, when one needs to leave for school).

\subsubsection{Budgeting}

Two apps deal with budgeting and managing one's money. One brings together students' bank accounts, credit cards, bills and investments so they know where they stand, see what they're spending and where they can save money and avoid late fees. Another app also teaches users better financial skills and helps them develop good spending habits, which become life skills that they can use in the future.

\subsubsection{Emails}

We all have the experience of having to deal with a large number of emails in our Inbox, including unwanted "subscriptions" to various sites. One of the email management apps helps students unsubscribe from unwanted emails with one click. It can also help students combine their favorite email subscriptions into a digest. Another app can schedule optimal times to send e-mails, "snooze messages," see if the recipient reads the email, and provide a reminder if someone does not reply to an email.

\subsection{Limitations}

We were not able to find information on the number of downloads for each app. Also, we do not provide ratings of the apps because these can be misleading when there are very few respondents. We do not provide the cost of the apps since these can change very quickly, although most are free or under $\$ 10$. Of course, some have trial periods, but again, this kind of information changes quickly, so we did not include this. However, the most serious limitation is that we are dealing with apps mentioned by single individuals and by experts, and not by numerous students with ADHD. Work in this area is currently proceeding in our laboratory.

\subsection{Implications}

Is it worth mentioning that there is not a lot in the literature about this topic. That leads us to question whether students 
are being sufficiently informed of the apps that might be useful. While most access specialists and campus disability service providers are aware that students with ADHD need schoolwork related assistance, it is important to note that being a successful student involves more than schoolwork. Academic success also requires a variety of coping skills to deal with daily life demands (Ahrens et al., 2019). For example, as CHADD (2018) noted, coping skills such as getting to school, going to bed to sleep, scheduling relaxation times, and managing one's budget are also important.

To function well academically requires that things in one's environment also function well. If students have no money to get to class, they don't get there. If students can't get to class because they have multiple jobs, they won't do well. If students don't have an alarm that wakes them, they may not get up in time for class.

\section{Conclusion}

The popular apps in the daily life demands category remind us that if access coordinators, campus disability service providers, and students with ADHD focus solely on schoolwork related apps, they will be missing an important part of the equation. They need to broaden their scope to ensure that students also have the help they need to structure and manage their daily life responsibilities, rather than just focusing on helping with schoolwork.

The end goal of the research was to compile a current and comprehensive list of apps, available in August 2020, related to coping with academic work by post-secondary students with ADHD. However, with the pace of change of technology and apps, it is probable that the list will become outdated in a short period of time. As the methodology and a list of relevant sources have now been described, there would need to be a willingness to update the list of apps at reasonable intervals.

There was no intention on our part to rate the apps as this would require students with ADHD to try using these. Apps were mentioned by single individuals and by experts, and not by numerous students with ADHD. Therefore, we included only those apps where at least three sources mentioned a schoolwork related app and where at least two sources mentioned a daily life demands app.

The next step is to gain more quantitative and qualitative information: first to ascertain what apps students with ADHD actually use - and their level of satisfaction with these - and second to interview, individually or in focus groups, postsecondary students with ADHD. Work has begun in this area in our laboratory. This interactive approach should further enrich our knowledge of apps for post-secondary students with ADHD.

\section{References}

Ahrens, B., Lee, M., Zweibruck, C., Tumanan, J., \& Larkin, T. (2019). The role of executive function skills for collegeage students. Graduate Independent Studies - Communication Sciences and Disorders, 19. https://ir.library.illinoisstate.edu/giscsd/19/

American Academy of Child and Adolescent Psychiatry. (2019, May). College students with ADHD. https://www.aacap.org/AACAP/Families_and_Youth/Facts_for_Families/FFF-Guide/College-Students-withADHD-111.aspx

Budd, J., Fichten, C., Jorgensen, M., Havel, A., \& Flanagan, T. (2016). Postsecondary students with specific learning disabilities and with attention deficit hyperactivity disorder should not be considered as a unified group for research or practice. Journal of Education and Training Studies (JETS), 4(4), 206-216. https://doi.org/10.11114/jets.v4i4.1255

CHADD. (2018, December 13). It's okay to put yourself first sometimes: Developing self-care. https://chadd.org/adhdweekly/its-okay-to-put-yourself-first-sometimes-developing-self-care/

Chmiliar, L., \& Anton, C. (2018). Mobile learning: Device ownership, usage, and perspectives of post-secondary students with and without disabilities. Journal on Technology and Persons with Disabilities, 6, 117-126. Retrieved from http://scholarworks.csun.edu/bitstream/handle/10211.3/202990/JTPD-2018-ID15-p117-126.pdf?sequence=1

DuPaul, G. J., Gormley, M. J., \& Laracy, S. D. (2013). Comorbidity of LD and ADHD: Implications of DSM-5 for assessment and treatment. Journal of Learning Disabilities, 46(1), 43-51. https://doi.org/10.1177/0022219412464351

Fichten, C. S., Jorgensen, M., Havel, A., King, L., Harvison, M., Lussier, A., \& Libman, E. (2019). More than meets the eye: A Canadian comparative study on PowerPoint use among post-secondary students with and without disabilities. International Research in Higher Education, 4(2), 25-36. https://doi.org/10.5430/irhe.v4n2p25

Gagné, Y., Tremblay, D., \& Bussières, M. (2020). Statistiques concernant les étudiants en situation de handicap dans les universités Québécoises: 2018-2019. AQICESH. https://www.aqicesh.ca/wp-content/uploads/2020/02/StatAqicesh-18-19-sans-universit\%C3\%A9.pdf

Gortsema, J. (2019). Using app-based organizational strategies to promote neurodiverse and typical students' success 
[Master's thesis, Florida State University]. Institutional Repository at Florida State University. https://diginole.lib.fsu.edu/islandora/object/fsu\%3A722528/

Green, A. L., \& Rabiner, D. L. (2012). What do we really know about ADHD in college students? Neurotherapeutics, 9(3), 559-568. https://doi.org/10.1007/s13311-012-0127-8

Kreider, C. M., Medina, S., \& Slamka, M. R. (2019). Strategies for coping with time-related and productivity challenges of young people with learning disabilities and attention-deficit/hyperactivity disorder. Children, 6(2). https://doi.org/10.3390/children6020028

Mayo Clinic. (2019, June 22). Adult attention-deficit/hyperactivity disorder (ADHD). https://www.mayoclinic.org/diseases-conditions/adult-adhd/symptoms-causes/syc-20350878

Păsărelu, C. R., Andersson, G., \& Dobrean, A. (2020). Attention-deficit/ hyperactivity disorder mobile apps: A systematic review. International Journal of Medical Informatics, 138. https://doi.org/10.1016/j.ijmedinf.2020.104133

Seilhamer, R., Chen, B., Bauer, S., Salter, A., \& Bennett, L. (2018, April). Changing mobile learning practices: A multiyear study 2012-2016. EDUCAUSE. https://er.educause.edu/articles/2018/4/changing-mobile-learningpractices-a-multiyear-study-2012-2016 


\section{Appendix A}

Published Sources for the Apps

ADHD Editorial Board. (2020, March 10). Three tools to ease the transition to college life. ADDitude. https://www.additudemag.com/tools-apps-ADHD-college-students-productivity/

Children and Adults with Attention-Deficit/Hyperactivity Disorder. (2019, January 24). App roundup: Helpful suggestions for 2019. https://chadd.org/ADHD-weekly/app-roundup-helpful-suggestions-for-2019/

Doyle, A. (2019, April 30). The best ADHD apps for 2019. Healthline. https://www.healthline.com/health/ADHD/topiphone-android-apps

Dr. Dawn. (2019, January 30). Five favorite ADHD apps for adults. ADHD Wellness Center. https://ADHDwellnesscenter.com/5-favorite-ADHD-apps-for-adults/

Friedlander, B. S. (2020, June 29). Eighteen assistive technology apps and extensions for struggling students. ADDitude. https://www.additudemag.com/assistive-technology-for-students/

Portsea, J. (2019). Using app-based organizational strategies to promote neurodiverse and typical students' success [Master's thesis, Florida State University]. Institutional Repository at Florida State University. https://diginole.lib.fsu.edu/islandora/object/fsu\%3A722528/

Guadagni, B. (2019, October 18). Fifteen best assistive learning tools for students with ADHD. ADDitude. https://www.additudemag.com/assistive-technology-education-applications-ADHD-students/

Guadagni, B. (2020, June 24). Apps and tools that boost reading, writing, and organization. ADDitude. https://www.additudemag.com/learning-apps-and-tools/

Josel, L. (2020, May 20). What productivity apps will keep my teen accountable and motivated? ADDitude. https://www.additudemag.com/productivity-apps-ADHD-teens-accountability/

Mackay, K. (2018, May 18). My favorite apps and tools for ADHD. https://lifeeffects.teva/us/articles/my-favorite-appsand-tools-for-ADHD-brains

Maitland, T. E. L. (2017, September 26). College? There's an app for that. ADDitude. https://www.additudemag.com/college-organization-apps/

McMahon, J. (2017, July 12). Seven iPhone apps that help me with my ADHD. Vice. https://www.vice.com/en_us/article/qvpzdv/7-iphone-apps-that-help-me-with-my-ADHD

Stallworth, B. (2019, November 22). Twenty-five apps that show your ADHD who's boss. Greatist. https://greatist.com/ADHD/top-iphone-android-apps-ADHD

Tivers, E. (2019, October 18). Thirty-eight apps and add-ons that transformed my productivity. ADDitude. https://www.additudemag.com/best-productivity-apps-ADHD-adults/

Tivers, E. (2019, October 18). Twenty-five great mobile apps for ADHD minds. ADDitude. https://www.additudemag.com/mobile-apps-for-ADHD-mi

\section{Copyrights}

Copyright for this article is retained by the author(s), with first publication rights granted to the journal.

This is an open-access article distributed under the terms and conditions of the Creative Commons Attribution license which permits unrestricted use, distribution, and reproduction in any medium, provided the original work is properly cited. 